\title{
Introduction to the special issue on Big Data in finance and business
}

\section{J. Christopher Westland ${ }^{1}$}

It is hard to remember that only 30 years ago, e-market innovation was led, not by marketing and commerce, but by the financial sector. The stock market crash of 1987 generated enormous interest in electronic trading, and within 5 years the number of stock markets nearly doubled, led by a boom in electronic trading platforms. Many technical innovations essential to electronic commerce were developed first in financial markets. We are today witnessing a new period of creative destruction in finance. Old-line banks and funds are being pushed aside by algorithmic traders; central markets by private equity and dark pools; and financial specialists by computer scientists. This special issue of ECR offers an exciting glimpse of cutting-edge research on the current wave of disruptive innovations in finance and business. I want to thank our guest editors, (Fujun Lai; Robert Xin Luo; Yunchuan Sun and Yufeng Shi), for their outstanding work in managing this special issue. We hope our readers find these articles stimulating as they expand the combined discourse on e-commerce, finance and business markets.

\section{J. Christopher Westland} westland@uic.edu

1 University of Illinois - Chicago, Chicago, IL, USA 